\title{
Editorial Comment: Does the Use of a Robot Decrease the Complication Rate Adherent to Radical Cystectomy? A Systematic Review and Meta-Analysis of Studies Comparing Open with Robotic Counterparts
}

\author{
Tzelves L', Skolarikos A ${ }^{1}$, Mourmouris P ${ }^{1}$, Lazarou L ${ }^{1}$, Kostakopoulos N ${ }^{1}$, Manatakis DK ${ }^{2}$, Kural AR ${ }^{3}$ \\ 1 2nd Department of Urology, Sismanoglio General Hospital, National and Kapodistrian University of Athens, Athens, Greece; \\ 2 1st Department of Surgical Oncology, St. Savvas Cancer Hospital, Athens, Greece; ${ }^{3}$ Department of Urology, School of \\ Medicine, Acibadem Maslak Hospital, Acibadem Mehmet Ali Aydinlar University, Istanbul, Turkey
}

J Endourol. 2019 Dec;33(12):971-984.

DOI: 10.1089/end.2019.0226 | ACCESS: 10.1089/end.2019.0226

Eliney F. Faria ${ }^{1}$

${ }^{1}$ Serviço de Urologia, Hospital Felicio Rocho, Belo Horizonte, MG, Brasil

\section{COMMENT}

In this paper the group of university of Athens, performed a very good review and meta-analysis (using PRISMA guidelines) about complication rates of robotic assisted radical cystectomy (RARC). Despite open radical cystectomy (ORC) remains the mainstay of treatment for muscle-invasive and high-risk nonmuscle-invasive bladder cancer decreasing complication rates was the main goal of development of minimally invasive alternative techniques. RARC has been transforming into a safe and efficient alternative to the open gold standard procedure (1-3). This meta-analysis is the largest in the literature comparing complication rates between open and RARC. The advantages in terms of peri- and postoperative outcomes of this minimally invasive procedure has remained contradictory. A higher level of evidence is usually extracted by well-designed, randomized control studies and seems to agree with their findings that do not award the robotic procedure any advantage in terms of complication rates when compared with its open counterpart (3-6). They analyzed 54 studies ( 5 randomized trials and 49 observational), including 29,697 patients (6,500 in the RARC group and 23,197 in the open radical cystectomy group). RARC was associated with lower blood transfusion rates $(p<0.001)$, lower length of stay $(p<0.001)$, faster return to regular diet $(p<0.001)$, 
and lower postoperative mortality rates $(\mathrm{p}<0.001)$, but longer operating time. They concluded RARC appears to be associated with fewer complications and favoring perioperative outcomes in comparison with the ORC. RARC is an efficient and safe procedure that can provide an alternative to the open procedure.

\section{CONFLICT OF INTEREST}

None declared.

\section{REFERENCES}

1. Antoni S, Ferlay J, Soerjomataram I, Znaor A, Jemal A, Bray F. Bladder Cancer Incidence and Mortality: A Global Overview and Recent Trends. Eur Urol. 2017;71:96-108.

2. Khan MS, Gan C, Ahmed K, Ismail AF, Watkins J, Summers $J A$, et al. A Single-centre Early Phase Randomised Controlled Three-arm Trial of Open, Robotic, and Laparoscopic Radical Cystectomy (CORAL). Eur Urol. 2016;69:613-621.

3. Bochner BH, Dalbagni G, Sjoberg DD, Silberstein J, Keren Paz GE, Donat SM, et al. Comparing Open Radical Cystectomy and Robot-assisted Laparoscopic Radical Cystectomy: A Randomized Clinical Trial. Eur Urol. 2015;67:1042-50.

\section{Eliney F. Faria, MD}

Serviço de Urologia, Hospital Felicio Rocho, Belo Horizonte, MG, Brasil

E-mail: elineyferreirafaria@yahoo.com.br

4. Messer JC, Punnen S, Fitzgerald J, Svatek R, Parekh DJ. Healthrelated quality of life from a prospective randomised clinical trial of robot-assisted laparoscopic vs open radical cystectomy. BJU Int. 2014;114:896-902.

5. Nix J, Smith A, Kurpad R, Nielsen ME, Wallen EM, Pruthi RS Prospective randomized controlled trial of robotic versus open radical cystectomy for bladder cancer: perioperative and pathologic results. Eur Urol. 2010;57:196-201.

6. Parekh DJ, Reis IM, Castle EP, Gonzalgo ML, Woods ME, Svatek RS, et al. Robot-assisted radical cystectomy versus open radical cystectomy in patients with bladder cancer (RAZOR): an open-label, randomised, phase 3, non-inferiority trial. Lancet. 2018;391:2525-36.
ARTICLE INFO

Eliney F. Faria

https://orcid.org/0000-0002-8297-3417

Int Braz J Urol. 2020; 46: 657-8 